\title{
Direito humano à alimentação adequada: um olhar urbano
}

\author{
The human right to adequate food: an urban vision
}

Juliana Pereira Casemiro ${ }^{1}$

Victor Vincent Valla*1

M aria Beatriz Lisboa Guimarães ${ }^{2}$

\footnotetext{
${ }^{1}$ Escola Nacional deSaúde Pública, Fiocruz. Rua Leopoldo Bulhões 1.480, M anguinhos. 21041-210 Rio deJaneiro RJ. julianacasemiro@gmail.com 2Instituto de Ciências Humanas, Departamento de Ciência da Religião, UniversidadeFederal de Juiz deFora.

${ }^{*}$ in memorian
}

Abstract The human right to adequate food is comprehended in two dimensions: being free of hunger and denutrition and having access to an adequate food. The urban context, in which the possession of food is done primarily through merchandising because of its strong consuming appealing, becamea bigchallengeto debatethis topic in poor districts today. Here we combine considerations of a qualitative study carried out in São João de M eriti, Rio de Janeiro State, joining leaders from Pastoral da Criança in focal group sessions. The unemployment, the sub-employment and the difficulty in reaching the public health system, the social assistance and basic sanitation were presented as the major obstacles to bring into effect the human right to food. It was possible to determine that, among the strategies to fight the poverty and hunger, a big highlight is the establishment of mutual help mechanisms. The social support, generosity and religiousness were presented as the most important categories among the thoughts of the leaders. Facing a reality in which poverty and hunger appear as something inherent or become a mechanism of change during elections, the issue of the clienteles appears as a huge concern and challenge for those leaders. Key words Human right to adequatefood, Popular participation, Pastoral da Criança, Hunger
Resumo 0 direito humano à alimentação adequada é compreendido em duas dimensões: estar livre da fome e da desnutrição e ter acesso a uma alimentação adequada ${ }^{1,2}$. No contexto urbano, com seu forteapelo ao consumo eem quea aquisição de alimentos se dá prioritariamente a partir de relações mercantis, debater este tema em bairros empobrecidos apresenta-se como grande desafio. Este artigo reúne reflexões realizadas a partir de um estudo qualitativo realizado em São J oão de M eriti, município localizado na Baixada Fluminense $(R J)$, reunindo líderes da Pastoral da Criança em sessões degrupo focal. 0 desemprego esubemprego e a dificuldade de acesso aos serviços públicos de saúde, assistência social esaneamento foram apresentados como principais obstáculos para a efetivação do direito humano à alimentação. Foi possível identificar que, dentre as estratégias de enfrentamento da pobreza e da fome, o estabelecimento de circuitos de ajuda mútua tem grande destaque. A poio social, dádiva ereligiosidadeapre sentaram-se como categorias relevantes nas reflexões dos líderes. Diantedeuma realidadeem quea pobreza ea fome ou são naturalizadas ou se revertem em moeda detroca duranteas eleições, a questão do clientelismo aparece como grande preocupação e desafio para estes líderes.

Palavras-chave Direito humano à alimentação adequada, Participação popular, Líderes da Pastoral da Criança 
Introdução

Ao debater o direito humano à alimentação ade quada (DHAA) no Brasil, deve-se ter como pressuposto que desnutrição, fome, pobreza e misé ria não se distribuem ao acaso. Ao contrário, são construções históricas, frutos de decisões tomadas pelas elites econômica epolítica denosso país, seduzidas por promessas de lucro farto e cúmplices deinteresses internacionais.

A gênese do que se constitui hoje como campo da segurança alimentar enutricional no Brasil tem íntima relação com o processo de redemocratização vivenciado na década de oitenta, ganhando grande impulso na década de noventa, quando se assiste por um lado o acirramento das desigualdades no Brasil e, por outro, uma intensa mobilização em torno da luta contra a fome e a miséria no país. A partir destes debates, constituiu-se 0 arcabouço legal eideológico que fundamenta 0 atual debate acerca do direito humano à alimentação adequada (DHAA) no Brasil.

O DHAA tem sido afirmado em âmbito internacional em diversos pactos e declarações e reafirmado no Brasil através da recente aprovação da Lei Orgânica de Segurança Alimentar e Nutricional, que "cria o Sistema Nacional de Segurança Alimentar e Nutricional - SISAN com vistas em assegurar o direito humano à alimentação adequada"3.

A fome, a má nutrição e a desnutrição são manifestações da violação do $\mathrm{DHAA}^{4}$. Em que pesem os atuais esforços articulados no campo de políticas públicas para o enfrentamento destas questões, ainda há muito que ser feito. Esse "que fazer" será mais efetivo quanto maior for seu nexo com as expressões cotidianas de violação do DHAA e quanto maior for sua capacidade de intervir nos determinantes históricos e ordinários de reprodução de fome, má nutrição e desnutrição - ainda uma realidade nos bolsões de pobreza urbanos.

Criada em 1983, a Pastoral da Criança atua em áreas pobres, tendo como temas a saúde da gestante, al eitamento materno, vigilância nutricional, reidratação oral e vacinação. Sua dinâmica do trabalho consiste em "capacitar" lideranças, que residem na própria comunidade, para atuarem junto a famílias no cuidado de crianças menores de seis anos. Sua atuação é ecumênica, apesar de constituir-se em órgão de assistência social da CNBB 5 .

Durante três meses, doze líderes da Pastoral da Criança de São João de M eriti reuniram-se em sessões de grupo focal. Complementarmente, foi utilizada a técnica de observação partici- pante com registro em diário de campo, com 0 intuito de transcrever falas que capturassem a visão destas lideranças sobre o D H AA e as manifestações de sua violação. 0 roteiro dos grupos focais e definição de categorias de análise das falas foram inspirados na definição de DHAA do Comentário Geral no 12 do Comitê de Direitos Econômicos, Sociais e Culturais da ONU. Sob a definição deste pacto, o DHAA implica obrigações do Estado e da sociedade em respeitar, proteger, promover e prover: a) acesso físico e econômico a uma alimentação saudável e diversificada de forma sustentável; b) condições que propiciem um cuidado adequado na escolha, preparação e ministração do alimento (higiene, preparação de alimentos, creche, etc.); c) condições de vida que promovam a saúdeed) atenção integral à saúde ${ }^{1}$.

A pesquisa foi realizada sob uma concepção denominada "investigação científica do ponto de vista popular", que Valla ${ }^{6}$ descreve a partir de reflexões de José Luís Corrágio. Sob esta perspectiva, trata-se de realizar uma pesquisa através de métodos e instrumentos científicos "porém à luz do olhar das classes populares". Valla ${ }^{6}$ apresenta esta estratégia como forma de realizar uma pesquisa que se posicione nas "lacunas" deixadas pelas informações veiculadas pel os meios de comunicação em massa e difundidas pelos governantes, que estão distantes de refletir o dia a dia das periferias 6 .

As análises apresentadas procuram captar as dinâmicas, os conflitos e as contradições expostos através das reflexões real izadas sobre atuação cotidiana dos líderes e de suas avaliações acerca das condições de alimentação e nutrição em suas comunidades e no município como um todo.

0 objetivo desteartigo éapresentar um "olhar urbano" sobre o DHAA, debatendo, a partir das falas de líderes da Pastoral da Criança, as condições de promoção e defesa do DHAA em São João de M eriti, Baixada Fluminense, Região M etropolitana do Rio de Janeiro.

\section{O contexto metropolitano e urbano}

A história tem mostrado que são raras as situações em que as sociedades humanas conseguem garantir uma alimentação de qualidade para todos os seus membros e, por isto, a defesa do DH AA começa pela luta contra a fome: "garantia a todos os cidadãos de ter acesso diário a alimentos em quantidade e qualidade suficiente para atender as necessidades nutricionais básicas essenciais para a manutenção da saúde" 7 . 
Nota-se o sentido abrangente do debate sobreDHAA. 0 complexo contexto metropolitano agrega novos desafios à interpretação das relações entrefome, pobreza e desnutrição. A fomeé produzida pelo contexto social, político, econômico e histórico, mas encontra seu significado e expressão no cotidiano.

Cabe, no entanto, registrar uma ressalva realizada por $M$ onteiro ${ }^{8}$ de que há uma inegável distinção entreos conceitos defome, pobreza edesnutrição, embora igualmentegraves eindesejáveis, eainda que compartilhem causas e vítimas, são fenômenos diferentes. Para o autor, o lançamento do Programa Fome Zero reaviva esta discussão.

Assumindo e resguardando tais diferenças conceituais, afirma-sequea existência defronteiras e permeabilidade entre os diagnósticos de fome, pobreza e desnutrição fazem parte dos debates realizados por esteartigo, uma vez que trata de um olhar que, por tomar emprestada uma lente popular, apresenta-se em calidoscópio. Ainda mais relevante é destacar que, no contexto urbano, são as relações mercantis que predominam quando se trata da aquisição de alimentos. $\mathrm{Na}$ fala de uma líder, "se você tem condições de uma renda, tem condições de uma boa al imentação".

Analisando o processo de urbanização no Brasil, constata-se que, se por um lado provocou algumas transformações que podem ser consideradas como avanços, por que são típicas deste processo em várias partes do mundo (tendência a uma diminuiç̧ão da taxa de mortal idade e crescimento da esperança de vida), por outro, destaca-se que, em grande parte, viver mais significa "sofrer as agruras de uma sociedade injusta e uma vida sem qualidade, submetidas a pressões e violências de todo tipo"9.

Em áreas urbanas metropolitanas, são mais evidentes os sinais de uma "nova pobreza" caracterizada pelo desemprego crescente e precarização das relações de trabal ho com suas cruéis consequências: escassez dos meios de sobrevivência, aumento da vulnerabilidade social e a instabilidade e a ausência de garantias nas relações de trabalho ${ }^{10,11}$.

Constata-se uma "perversa superposição, em que pobreza e desigualdade social assumiram uma também crescente complexidade, agregando 'novos pobres' ao contingente de 'antigos pobres' ou miseráveis"10. Dito de outra forma, "às parcelas da população historicamente marginalizadas econômica esocial mente, soma-seum novo contingente de trabalhadores empobrecidos"11.

0 processo de "metropolização da pobreza" 10 destaca-se como uma tendência atual dos países em desenvolvimento, que encontra grande contribuição na estagnação econômica: 0 capitalismo de hoje prescinde do trabalho, particularmente em capitalismos como os nossos, periféricos e dependentes. Trata-se de lucrar com o capital financeiro enão de investir na produção ou na atividade econômica que gera emprego e renda ${ }^{10}$.

Em nosso país, estefenômeno está relacionado à mudança da "feição da pobreza no Brasil" ${ }^{12}: 0$ país deixa de ser rural para ser urbano, principalmente metropolitano. Em 1950, as metrópoles concentravam $17 \%$ da população brasileira, chegando a 29\% em 1980 ea 30\% em 1996 (46,1 milhões depessoas) $)^{12}$. Estefortecrescimento populacional foi acompanhado por um empobrecimento relativo, já que os "grandes contingentes migrantes afluindo às metrópoles era formado por pobres rurais, os quais se transformavam em pobres metropolitanos"13.

No Rio de Janeiro, a pobrezaé essencialmente metropolitana. A metrópole concentra $85 \%$ dos pobres do estado, isto devido a dois fatores: ao tamanho da população metropolitana ( $77 \%$ da população do estado) e por ela apresentar a mais elevada proporção de pobres $(33 \%)^{14}$. Seguindo uma tendência comum a outras metrópoles de países em desenvolvimento, apresenta uma proporção de pobres mais elevada nas periferias que nos núcleos. Enquanto no núcleo a proporção de pobres era de $25 \%$, na periferia era de $41 \%$, consequência da "periferização combinada ao empobrecimento da metrópole como um todo durante a década de 1980"13.

São João de M eriti éum dos treze municípios que compõem a Baixada Fluminense, na Região M etropolitana do Rio de Janeiro. N esta cidade, a dinâmica deocupação intensa tem início na década de quarenta. Cresceatravés de loteamento, em sistemas de autoconstrução, "pequenas habitações e mais de uma unidade por lote"15. Emancipada em 1947, está localizada a 35 quilômetros da capital do estado e suas principais atividades econômicas são a indústria e o comércio.

A questão do acesso à moradia, ao saneamento eà água aparececomo preocupação recorrentee que os líderes relacionam com a violação do DHAA: "É um bando de casinha assim, não tem sanitário, ese vocêpassa um ano, dois, trêsvisitando aquela família a realidade é a mesma".

Atualmente, São João de M eriti tem $100 \%$ da população vivendo em área urbana, com 148.920 domicílios em seus $34,7 \mathrm{Km}^{2}$. Seu território corresponde a $0,08 \%$ da área total do estado; contudo, sua população corresponde a 3,13\% da população do estado. Com uma população de 449.476 
habitantes, possui uma das maiores densidades demográficas do país com 12.901 hab/km²,16,17.

\section{A definição do DHAA ea vulnerabilidade}

A parecem no discurso dos líderes características essenciais relacionadas ao di reito humano: a universalidade, indivisibilidade e interdependência dos direitos e respeito à diversidade. Destacam que a simples constatação da alimentação enquanto um direito não é o suficiente para garantir 0 acesso.

A imprevisibilidade, a instabilidade e a sensação de vulnerabilidade a que são expostas as famílias fizeram parte do discurso com grande ênfase ao desemprego e ao subemprego (referido como biscate) como principais obstáculos à garantia do direito humano à alimentação adequada. De forma inversa, para que seja alcançado o DHAA deve haver "em primeiro lugar éum salário digno". Para o grupo, a maioria das famílias convive com a ameaça da fome porque quem "trabalha de biscate, sabe que no final do mês não dá para completar a bolsa de alimentação". Consideram "salário digno" como aquelequevem todos os meses, que "é para a família" e que garante a alimentação durante o mês inteiro: "saber se ela tem aquele salário, mas dentro do mês".

Os períodos de desemprego agravam a situação de vida das famílias pobres e jogam na pobreza famílias antes "incluídas", trazendo novas situações de instabilidade e de "semipobreza". 0 desemprego firma-se como um dos principais determinantes da pobreza e da desigualdade. Soares ${ }^{10}$ alerta sobre uma concentração do de semprego em áreas metropolitanas, que "embora tenha atingido a todos os setores da sociedade, se mantém com taxas elevadas nas famílias de mais baixa renda e nos jovens" ${ }^{10}$.

Há a percepção de que não bastam atividades informais ou a confecção de produtos com pouco (ou sem) valor de comércio para solucionar os problemas porque "artesanato barato não vende, porqueninguém quer. $\mathrm{Oh}$, já dizia Joãozinho Trinta: Pobre gosta de luxo, não gosta de pobreza!" No entanto, al gumas das falas encontram associação entre o oferecimento de atividades que gerem trabalho e renda e a recuperação da autoestima das mães.

A escolaridade é vista como uma alternativa de alcançar o status de assalariado e à educação formal é imputada a responsabilidade de ser única (e última) alternativa. Esteé um dos reflexos de um processo de mudança do papel da educação, que segundo Soares ${ }^{10}$ deixa de ser um direito de cidadania ou possibilidade de libertação (lembrando Paulo Freire) para transformarse em precondição para a competitividade.

Existe uma percepção da vulnerabilidade das mulheres, sobretudo chefes de família e mães solteiras, obrigadas a criar artifícios para garantir sua sobrevivência e de sua família. M uitos"sacrifícios" estão relacionados a uma tentativa de aproximar-se aos atuais padrões estéticos e de consumo da sociedade. 0 corpo nesta negociação torna-se apenas mais uma mercadoria: uma "troca árdua", mas é uma troca: "É isso que a gente tem observado em termos de segurança alimentar em busca do alimento como está sendo feita a troca árdua".

Os jovens aparecem como preocupação, porque há uma constatação de que uma grande parte das crianças acompanhadas pelos líderes têm "pais muito jovens", geralmente desempregados, e iniciando a vida profissional. Agrega-se a esta vulnerabilidadea questão da gravidez naadolescência, preocupação cada vez mais frequenteentre os líderes: "Eu estava com quinze barrigudas. A mais velha no meu caderno tinha dezoito anos, a mais velha".

\section{O acesso aos serviços públicos ea violação do DHAA}

0 intenso processo de urbanização do país deixou suas marcas, principalmenteno queserefere ao acesso a políticas públicas, como saneamento e saúde, e também no que tange à falta de políticas de ocupação do espaço e de controle da de-

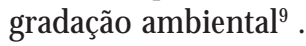

O acesso aos serviços públicos de saúde, assistência social e saneamento foram apresentados como grandes obstáculos para a efetivação do DHAA. O grupo diagnosticou que esta desassistência dos governos dá origem ao que chamaram de "papel invertido". Na lógica da atuação da Pastoral da Criança, os líderes encaminham (e denunciam) demandas sociais e de saúde ao poder público para que este dêas respostas cabíveis. Quando as demandas apresentadas pelas famílias e pelos líderes não são acolhidas e resolvidas pelos serviços públicos, este "papel invertido" se manifesta: "eu tinha a ilusão e eu passava isso para as líderes, que a família que estivesse numa situação de carência muito grande ou determinadas necessidades que poderiam ser encaminhadas. Nada estava funcionando. Recebo bilhetes de assistentes sociais que mandam me procurar, já me procuraram até para comprar remédio". 
Revelam-se pelas falas vários artifícios e ataIhos desenvolvidos pelas mães e pelos líderes para de acessar de alguma forma os serviços, sobre tudo exames einternações. 0 "acesso" através de "conhecimentos" ou "contato político" foi relatado várias vezes. Ultrapassada a barreira do acesso aos serviços públicos de saúde, o desafio torna-se encontrar meios de seguir orientações e prescrições: “médico, el efoge da realidade, elenão está preparado pra poder conversar com essas pessoas e vai encaminhar pro nutricionista, fica passando aquilo ali tudo pra mãe pra levar para casa uma receita".

0 "papel invertido" também érelatado quando, segundo os líderes, os profissionais de saúde não conseguem lidar com as demandas sociaise passam a "encaminhar" famílias para a Pastoral da Criança: "Os pediatras, quando pegam essas famílias miseráveis, ele mesmo vê, pega caso de desnutrição, ele não tem para onde encaminhar, ele encaminha para a Pastoral".

Nesta análise das ações do poder público, travou-se também um debate sobre o clientelismo. 0 contexto de tantas necessidades e demandas não atendidas torna-se terreno fértil para que serviços e favores virem troca de moeda: "Você não consegue ver uma transformação ou uma esperança no olhar de cada um, porque há sempre aquela troca meio de voto, meio de alguma coisa pra poder estar votando neles".

Farias $^{18}$ afirma que uma ampla corrente da ciência política resume o debate a uma oposição entre o clientelismo (barganha político-eleitoral) ea democracia sob dois argumentos: (1) o clientelismo éa apropriação privada da coisa pública, (2) a barganha do voto representa uma corrupção da democracia.

\section{"Consumo logo existo"19}

Sabe-se que a cultura guarda forte relação com os hábitos e escolhas alimentares que são certamente também influenciados pelo contexto social, político, econômico eambiental mais amplo ${ }^{20} .0$ alimento tem na sociedade humana múltiplos papéis esignificados: cria esustenta relações sociais, sinaliza status social eocupacional epapeis de gênero, marca mudanças importantes na vida, (aniversários e festividades) e reafirma identidades - religiosas, étnicas ou regionais ${ }^{20}$.

0 debateacerca de hábitos alimentares não se restringe, portanto, ao plano biológico ou às necessidadesfisiológicas. A alimentação éuma construção cultural, tem caráter simbólico “cujo signifi- cado se dá na trama das relações sociais" ${ }^{21}$, sendo "referenciada pelos diferentes perfis de consumo compartilhados em cada sociedade que criam expectativas e valores em torno do processo" 22 .

No contexto urbano, com seu forte apelo ao consumo e em que a aquisição de alimentos se dá prioritariamente a partir de relações mercantis, o debate sobre o direito à alimentação em bairros empobrecidos apresenta-se como grande desafio. Sobre isto, uma líder diz: "H oje em dia moda disso, moda daquilo que a própria mídia vem trazendo. E aqueles que não têm? São crianças com a mesma vaidade de outras".

Segundo Stotz ${ }^{23}$, a pobreza "diz respeito a uma situação na qual uma pessoa (ou uma família) não tem condições de viver dentro dos padrões socialmente estabelecidos em um certo momento histórico"23. Deve-se, portanto, estabelecer uma reflexão sobre quais são e como se manifestam estes padrões no cotidiano urbano.

A alimentação, sobretudo no cenário urbano modernizante, combina tradições e novos padrões alimentares: interagem de diferente maneiras a "produção e reprodução de crenças alimentares [...] com os valores do mundo moderno, globalizado" 24 .

Em um texto recente sob o sugestivo título "Consumo logo existo", Frei Betto debate as novas relações estabelecidas entre a alimentação e os padrões de consumo rigidamente ditados por uma "sociedade de consumo". 0 alimento convertido dedireito àmercadoria. 0 val or simbólico damercadoria figura acima de sua utilidade, o ser humano se restringe ao ser consumidor e, àqueles privados do consumo, éreservado o espaço da exclusão que "causa frustração, depressão e infelicidade"19.

A mídia contribuí para a rápida divulgação de novos padrões de consumo, agregando novos desafios ao cotidiano de famílias e líderes. Estas mudanças interferem tanto nas escolhas quanto nas estratégias desobrevivência: "tem criançasque não conhecem determinados alimentos porque eles não têm esse acesso. Eles teriam direito de comer Danoninho, tomar iogurte, eles só vêm aquilo lá no programa de televisão. Seria um direito deles. É uma discriminação".

Outra vez, a questão dos jovens traz à tona grandes preocupações para os líderes, que ressaltam as consequências deum padrão externo (imposto ou assimilado) de consumo, um padrão em que a "realidade que dentro da pobreza, dentro da miséria eles não têm como viver, a não ser se prostituindo, indo pra o mundo das drogas".

Esta fala abre espaço para muitos debates e por ora vale apenas como reflexão ressaltar que 
as atividades ilícitas, na medida em que geram renda e estão com as "portas abertas", vêm se banalizando e transformando-se em mais uma estratégia de acesso e consumo. Parte da população "sobrante" criada pelo capitalismo encontra no crime organizado uma possibilidade de sobrevivência, abrindo as portas a jovens miseráveis nas favelas e bairros populares, já que "o capitalismo transforma tudo em mercadorias", não importando origem e natureza ${ }^{23}$.

Cabe também refletir a proposta de integração degrupos "marginalizados" quepartedo princípio de que uma parte da população, em razão da sua pobreza, encontra-se "fora" da sociedade. A dificuldade de acesso aos produtos e serviços básicos seria decorrência da ignorância e passividade desses excluídos - os que estão "fora"' por sua própria culpa, precisando ser incentivados e esclarecidos para poderem participar dos benefícios do processo econômico ecultural. A verdade éque estes grupos nunca deixam defazer parteda sociedade, mas sua participação na riqueza produzida se dá de forma desigual ${ }^{25}$.

\section{As estratégias cotidianas}

As sobras de feiras livres foram insistentemente apontadas como única opção de abastecimento para as famílias mais vulneráveis e muitos relatos de constrangimentos foram apresentados. Para os líderes, parece ser questão conflituosa: por vezes incentivada como única alternativa e por outras reconhecendo seus aspectos negativos: "a mãe que não tem, ela vai na feira e ela tem vergonha, ela se sente mais diminuída, a autoestima precisa ser trabalhada para que elas retornem ao meio social onde elas se sintam alguém, onde elas se sintam digamos que gente, porque elas não se sentem gente, elas acham que elas não existem. E nós perguntamos para nós mesmos isso: ela existe?"

A fala quequestiona se aquela mãe "pode existir" expõe um conflito entre o que orientam e 0 queverdadeiramente sentem os líderes. São muitos os constrangimentos apresentados nas falas: o fato de algumas vezes as mães terem que "disputar" as sobras com animais, a possibilidade de terem seu pedido negado, a doação ser a única opção que a mãe possui por não ter dinheiro al gum, a possi bilidade de encontrar-se com vizinhos e ter que expor situações extremas e "íntimas" de sua família. Por todos estes fatores, esta alternativa, apesar de toda a boa vontade dos líderes, torna-se um caso clássico de violação do direito humano à alimentação: é humilhante e degradante, não garante nem qualidade nem quantidade e impossibilita o direito de escolha e 0 acesso de forma digna à alimentação.

Condenada academicamente e alvo de constantes críticas, a Multimistura tem deixado deser consenso dentro da própria Pastoral da Criança, mas para os líderes, parece ter um apelo místico e humanitário. A Multimistura é uma farinha obtida a partir da mistura de subprodutos: farelos de trigo e arroz, farinha de trigo torrada, fubá, folhas verde-escuras, pó de sementes e de casca de ovo. Não tem eficácia comprovada no combate à desnutrição, seu conteúdo nutricional assemelha-se muito ao de outras farinhas ${ }^{26}$.

Há forte crença em sua eficácia, sendo atribuídos outros significados: doação, criação de vínculo com a família e celebração de um sentimento de "dever cumprido": "os líderes se apegam na Multimistura, no leite forte, que a gente sabe que não é isso que transforma, mas dá um poder de transformação para o próprio líder porque pelo menos elese sente levando al go para aquelas famílias".

Outro destaque observado nas falas é a doação de alimentos, cestas e de sobras por "pessoas que colaboram". Em um contexto de urgências, determina a convivência com situações constrangedoras que acabam sendo aceitas e legitimadas pelas ações cotidianas, ainda quese destaqueque "tudo isso deixa ela [mãe] muito caída, nem sempre ela vai pegar alimento, tem vergonha de pedir. É humilhante".

A autoestima aparece como desafio aos líderes e às famílias e étrabal hada numa perspectiva de mudar o mundo de dentro para fora. Há uma tentativa diária de recuperar a dignidade e a autoestima. N este sentido, as angústias são geradas porque os problemas são exteriores aos indivíduos e porque parecem (e são) muito maiores do que a capacidade de interven ção individual e mesmo coletiva.

\section{Sobre apoio social, dádiva e religiosidade}

Apoio social, dádiva e religiosidade aparecem nas falas dos líderes relacionados à motivação e às suas estratégias. A pesar de serem falas carregadas de sofrimento edeuma revolta contida, fica claro que, para líderes e famílias que coabitam sob esta escassez (de serviços públicos, de renda, de comida), há um grande valor do compartilhar.

A importância do estabelecimento de circuitos de ajuda mútua ${ }^{27,28}$ fez parte da descrição do 
cotidiano, trazendo a reflexão sobre a questão da dádiva, entendida como a prestação de serviço sem garantia de retorno, com vistas a criar, alimentar ou recriar os vínculos sociais entre as pessoas ${ }^{27}$

A teoria da dádiva foi sintetizada pelo antropólogo, etnólogo e sociólogo M arcel M auss em 1924, sob o título Ensaio sobre Dádiva ${ }^{29}$. N a década de oitenta, surge na França o M.AU.S.S. M ovimento Antiutilitarista nas Ciências Sociais. $M$ artins ${ }^{29}$ alerta que os debates sobre dádiva a partir da síntese de $M$ arcel M auss tem uma visão ampla que extrapola o senso comum estabelecido sobre dádiva, identificada como caridade ou benção. Segundo o autor, caridade e bênção correspondem a um tipo de dádiva: a cristã. Acrescenta ainda que a dádiva seria a definida pela universalidade de uma tripla obrigação de "dar, receber e retribuir" 29 .

Falando sobre sua motivação, um dos líderes ressalta: "Puxa, não somos parentes, mas temos laços". Estes são laços solidários e múltiplos, que partem do reconhecimento de que é preciso enfrentar o isolamento. Isto apareceu como uma preocupação: "Hoje em dia, a gente vive uma cultura assim, é um egoísmo, não é? Cada um vai vivendo a sua vida, ninguém se preocupa com ninguém. Ninguém ama ninguém".

Para Goldbout ${ }^{27}$, há uma recusa moderna em reconhecer a dádiva porque el a representa a imagem invertida do interessematerial egoísta eporque existe a influência da maneira pela qual a tradição do pensamento utilitarista permite a organização destas questões.

Ainda com relação a estes circuitos de ajuda mútua, deve-se acrescentar que muitos(as) líderes ingressam na Pastoral da Criança após anos de experiência como pais ou mães de crianças acompanhadas. São inúmeros os relatos sobre "ganhos" em relação à saúde e bem-estar daqueles que pertencem a este grupo. Desta forma, aproxima-se da abordagem de apoio social: re cursos emocionais, materiais e de informação que os sujeitos recebem por meio de relações sociais sistemáticas, num processo recíproco que gera efeitos positivos tanto para quem recebe como para quem oferece 0 apoio e que permite que ambos tenham uma sensação de coerência de vida e maior sentido e controle da mesma ${ }^{30}$.

Desta forma, Valla et al. ${ }^{30}$ destacam que este tipo de sentimento - de que uns precisam dos outros - remete-nos à dimensão da "integralidade na aten ção e no cuidado à saúde", fazendo emergir a necessidade de que se investigue "o papel das emoções e do apoio social no processo de saúde-doença". Ressaltam ainda que a rede de saúde pública (centros municipais de saúde e hospitais) tem importância reconhecida pela população sobre suas condições de vida e saúde, "mas há também a percepção de quemuitos problemas de saúde não podem ser resolvidos nesses locais"30.

A "esperança de que um dia vai mudar" foi assinalada como o principal motivador da atuação destes líderes que, ocupando-se das urgências cotidianas, protestam silenciosamente, adiando projetos econfiando no futuro queéincerto e por isso passível a mudanças.

As falas parecem demonstrar que, quando os problemas são considerados grandes demais para serem resolvidos no presente ou quando estão fora do campo de visão-ação dos líderes, a esperança torna-se um abrigo. A esperança num futuro que é incerto e por isso mesmo mutável. A esperança que existam mudanças para melhor.

Segundo Valla ${ }^{31}$, não se pensa no futuro (previsão) porque todas as energias estão mobilizadas para evitar a sensação de fome que já havia passado, egarantir a subsistência no dia de hoje (provisão) ${ }^{31}$. Desta forma, a naturalização das práticas clientelistas fazem todo o sentido para as classes populares que vivem sob a influência das urgências do presente.

\section{Consideraçõesfinais}

Este artigo apresenta reflexões iniciais sobre temas complexos e polêmicos. Ao utilizar "Ientes" emprestadas pelos líderes da Pastoral da Criança deSão João de M eriti, pretendeu-se aproximar o foco sobre o direito humano à alimentação adequada. Um olhar que não se afirma nem como neutro nem tampouco como definitivo. Ao realizar uma "investigação científica do ponto de vista popular", procurou-se valorizar a voz destas lideranças que alertaram: "a gente é o termômetro da comunidade". Não há a pretensão de esgotar o assunto; muito pelo contrário, pretendese contribuir para que seja provocado o debate, incomodar a comodidade tanto do "ser especialista" quanto do "ser organização da sociedade civil" na clausura de suas certezas e incertezas.

Como principais obstáculos à efetivação do DHAA, foram apresentados o desemprego e subemprego (a falta de "salário digno") e a dificuldade de acesso aos serviços públicos. Chama especial aten ção a denúncia sobre o "papel invertido" estabelecido na relação entresociedadecivil e governo (ou voluntário e profissional de saú- 
de). Esta constatação mostra que a tão propagada intersetorialidade ainda é campo conflituoso. É preciso que ambos os lados sejam ouvidos e se deixem ouvir, que apresentem fragilidades, necessidades e potencialidades.

Ainda sobre o "papel invertido", cabe uma re flexão futura sobre qual o papel dos municípios diante dequestões relacionadas ao DHAA. A partir do Programa Fome Zero, foram apresentadas estratégias efontesfederais definanciamento deações, mas também condicionalidades às famílias e exigências de contrapartidas dos governos locais.

Ainda que as falas tenham revelado críticas acerca das ações poder público, elas ao mesmo tempo carregaram-se de desalento ao tratarem do clientelismo e do controle público sobre as ações do governo. Ao quetudo indica, estesentimento de desalento tem influenciado negativamente na participação destas lideranças. A autêntica participação popular ébem mais queum "convite" do governo à população para que realize "com seu próprio trabalho" o que é da responsabilidade do governo: refere-se a uma multiplicidade de ações que devem ser desenvolvidas a fim de "[...] influenciar a formulação, execução, fiscalização e avaliação das políticas públicas e/ou serviços básicos na área social - saúde, educação, transporte, saneamento básico ${ }^{32}$.

Frente aos desafios cotidianos, surgem as mais diversas estratégias de enfrentamento de proble- mas cotidianos, dentre as quais há que se destacar a questão do apoio social edos circuitos de dádiva. Ainda que sejam mencionadas a Multimistura, as sobras de feiras, os lanches comunitários e as cestas básicas, cabe ressaltar que a circulação destas alternativas se faz a partir de relações de reciprocidade e solidariedade, como forma de defesa frente a uma "cultura do egoísmo" tão propagada pela modernidade capitalista. Ao transformar tudo (e todos) em mercadoria, a sociedade capital ista cria e reproduz miséria, fome, exploração, desemprego/subemprego e a falta de saúde, de água, de terra, de moradia digna, de educação. Aos "sobrantes" 23 , resta encontrar estratégias de enfrentamento frente a esta nefasta realidade.

A plena efetivação do DHAA se dará a partir de relações intersetoriais e, sobretudo, de uma profunda esincera mudança de cultura, que desnaturalize as situações de opressão e violação de direitos. Compreender a forma como estas lideranças e famílias avaliam e (res) significam sua realidade, captando a lógica de suas estratégias, pode significar um bom ponto de partida para 0 estabelecimento da autêntica participação popular e de parcerias mais justas, éticas e duradouras. Do ponto de vista de seus efeitos mais imediatos, este exercício de mútua escuta podequalificar as análises sobre a famosa queixa de muitos profissionais sobre a "falta de adesão ao tratamento e ao estilo de vida saudável".
Colaboradores

JP Casemiro, VV Valla e M BL Guimarães participaram igualmente de todas as etapas da elaboração do artigo. 


\section{Referências}

1. Comitê Nacional para a Implementação do Direito Humano à Alimentação Adequada. Promovendo a exigibilidade do direito humano à alimentação adequada: subsídios para debate. Brasília: COM IDhA; 2006.

2. Organização das Nações Unidas. Comentário Geral número 12: 0 direito Humano à Alimentação. Comitê de Direitos Econômicos, Sociais e Culturais do Alto Comissariado de Direitos Humanos da ONU. [site da Internet] [acessado 2007 jul 12]. Disponível em: http://www.abrandh.org.br/index.php?arquivo $=$ artigos 1999

3. Brasil. Lei $n=11.346$ de 15 de setembro de 2006 . Cria o Sistema Nacional de Segurança Alimentar e Nutricional - SISAN com vistas em assegurar 0 direito humano à alimentação adequada. Diário Oficial da União 2006; 15 set.

4. Valente FLS. Fome, Desnutrição e Cidadania: Inclusão Social e Direitos Humanos. Saude soc. 2003; 12(1):51-60.

5. Pastoral da Criança. 0 que fazemos. M etodologia. [site da Internet] [acessado 2006 jan 20]. Disponível em: http://www.pastoraldacrianca.org.br

6. Valla VV. Educação e saúde do ponto de vista popular: procurando compreender a fala das classes populares. In: Ramalho JP, Arrochellas $\mathrm{MH}$, organizadores. Desenvolvimento, sustentabilidade e trabalho informal no Brasil. São Paulo: Cortez/Centro Alceu Amoroso Lima para a Liberdade; 2004. p. 137-154.

7. Valente FLS. Direito humano à alimentação: desafios e conquistas. São Paulo: Cortez; 2002.

8. Monteiro CA. A dimensão da pobreza, da desnutrição e da fome no Brasil: implicações para políticas públicas. Estud. av. 2003; 17(48):7-20.

9. Pádua JA. Desenvolvimento humano e meio ambiente no Brasil. In: Moser $C$, Rech D, organizadores. Direitos humanos no Brasil: diagnóstico e perspectivas olhar dos parceiros de Misereor. Rio de Janeiro: CERIS/ MAUAD; 2003. p. 47-69.

10. Soares LT. Política e movimentos sociais. In: Sader $E$, organizador. Governo Lula: decifrando enigmas. São Paulo: Viramundo; 2004. p. 11-60.

11. Valla VV. Globalização, a questão social e a nova pobreza. In: Valla VV, Stotz EM, Algebaile EB, organizadores. Para compreender a pobreza no Brasil. Rio de Janeiro: Contraponto/Escola Nacional de Saúde Pública; 2005. p. 33-52.

12. Rocha S. Opções metodológicas para a estimação de linhas de indigência e de pobreza no Brasil. Texto para discussão no 720. Rio de Janeiro: IPEA; 2000.

13. Rocha S. Pobreza no Brasil: afinal do que se trata? Rio de Janeiro: FGV; 2003.

14. Rocha S. Tendência evolutiva e características da pobreza no Rio de Janeiro. Texto para discussão no 536. Rio de Janeiro: IPEA; 1997.

15. Torres G. Saneamento da Baixada Fluminense. [site da Internet] [acessado 2004 jul 13]. Disponível em: http://www.ipahb.com.br/saude_sanea.php

16. Fundação CIDE. Baixada Fluminense em Dados. [site da Internet] [acessado em 2004 jul 28]. Disponível em: http://www.cide.rj.gov.br

17. Instituto Brasileiro de Geografia e Estatística. São João de M eriti-RJ: Síntese. [site da Internet] [acessado 2004 ago 10]. Disponível em: http://www.ibge.gov. $\mathrm{br} / \mathrm{cidadesat}$
18. Farias FP. Clientelismo e democracia capitalista: elementos para uma abordagem alternativa. Rev. Sociol. Polit 2000; 15:49-65.

19. Betto F. Consumo logo existo. [site da Internet] [acessado em 2007 set 12]. Disponível em: http://www. adital.com. br/site/noticia. asp?lang $=P T \& \operatorname{cod}=24552$

20. H elman CG. Cultura, saúde $\&$ doença. Porto Alegre: Artmed; 2003.

21. Daniel JMP, Cravo VZ. Valor social e cultural da alimentação. In: Canesqui AM, Garcia RWD, organizadores. Antropologia e nutrição: um diálogo possível. Rio de Janeiro: Fiocruz; 2005. p. 57-68.

22. Burlandy L. Transferência condicionada de renda e segurança alimentar e nutricional. Cien Saude Colet 2007; 12(6):1441-1451.

23. Stotz EN. Pobreza e capitalismo. In: Valla VV, Stotz $E M$, Algebaile EB, organizadores. Para compreender a pobreza no Brasil. Rio de Janeiro: Contraponto/ Escola Nacional de Saúde Pública; 2005. p. 53-72.

24. Freitas MCS, Pena PGL. Segurança alimentar e nutricional: a produção do conhecimento com ênfase nos aspectos culturais. Rev. Nutr. 2007; 20(1):69-81.

25. Valla VV. Sobre a participação popular: uma questão de perspectiva. Cad Saude Publica 1998; 14(Supl 2):7-18.

26. Azeredo VB. Multimistura: uma alternativa alimentar? Rio de Janeiro: Universidade Federal Fluminense; 1999.

27. Godbout JT. O espírito da dádiva. Rio de Janeiro: FGV; 1999.

28. Martins PH. A dádiva entre os modernos: discussões sobre os fundamentos e as regras do social. Petrópolis: Vozes; 2002.

29. Martins PH. A dádiva e sua importância teórica para se pensar as relações entre Estado, mercado e comunidade. [site da Internet] [acessado 2007 dez 18]. Disponível em: http://www.ces.uc.pt/lab2004/inscricao/propostas/pdfs/phmartins.pdf

30. Valla VV, Guimarães MB, Lacerda A. Religiosidade, apoio social e cuidado integral à saúde: uma proposta de investigação voltada para as classes populares. In: Pinheiro R, M attos RA, organizadores. Cuidado: fronteiras da integralidade. Rio de Janeiro: CEPES/UERJ/Abrasco; 2006. p. 103-117.

31. Valla VV. 0 que a saúde tem a ver com a religião? Religião e cultura popular. Rio de Janeiro: DP\&A; 2001.

32. Valla VV. Controle social ou controle público? Uma contribuição ao debate sobre controle social. In: Wendhausen A. Duplo sentido do controle social: descaminhos da participação em saúde. Santa Catarina: Univali; 2002. p.14.

Artigo apresentado em 05/01/2008 Aprovado em 16/04/2008 